W. GORDIJ N

\title{
CULTURELE ONTWIKKELINGEN IN RIJKSVERBAND
}

\begin{abstract}
De drie landen van het Koninkrijk zullen echter alleen dan een sterke innerlijke gemeenschap kunnen vormen wanneer daaraan mede ten grondslag ligt het besef van een geestelijke verwant schap. Om dit besef te doen groeien is een voortgezette ontmoeting op geestelijk gebied nodig. ${ }^{1}$
\end{abstract}

De culturele ontwikkeling in Rijksverband tussen de jaren I954 en 1964 is zo veelomvattend, dat het niet mogelijk is daarvan binnen het kader van de beschikbare plaatsruimte een gedetailleerde beschrijving te geven. In het eerste deel van deze beschouwing zal hetgeen gedurende de afgelopen periode is gebeurd in algemene zin worden belicht; in het tweede deel zal de aandacht vallen op enkele sectoren afzonderlijk; tenslotte zal worden uiteengezet wat naar mijn mening nodig is om verzekerd te blijven van een ongestoorde verdere groei van hetgeen gedurende het thans achter ons liggende decennium gestalte kreeg.

Het jaar I954 markeert voor wat het onderwerp betreft geen begin of eindpunt zoals dit het geval is met de staatkundige verhoudingen tussen de drie landen van het Koninkrijk. Op vele terreinen van het culturele leven werden activiteiten ontplooid, welke reeds vóór I5 december I954 en ten dele zelfs in de eerste jaren na I945 waren begonnen.

Dat wil niet zeggen, dat de totstandkoming van het Statuut voor de culturele ontwikkelingen van weinig of geen belang zou zijn geweest. Het Statuut onderscheidt zich van andere soortgelijke staatsrechtelijke documenten alleen al door het feit, dat het een culturele paragraaf omvat, die de financiële armslag voor het ontplooien van activiteiten in dit veld, zij het in langzaam tempo, groter heeft gemaakt.

1 Uit de rede van prof. dr. L. J. M. BEEL, bij de installatie van het bestuur van de 'Nederlandse Stichting voor Culturele Samenwerking met Suriname en de Nederlandse Antillen' (STICUSA), in 1956. 
Mr. R. H. Pos heeft er echter reeds op gewezen, ${ }^{1}$ dat gevoelens van geestelijke verwantschap vaak duurzamer zijn gebleken dan de staatkundige band. Het zijn deze gevoelens, die reeds vóór I954 een culturele samenwerking mogelijk maakten en het zullen mogelijk dezelfde gevoelens zijn, die een dergelijke samenwerking zullen bestendigen ook nadat in een min of meer verwijderde toekomst de staatkundige verhoudingen eventueel opnieuw gewijzigd zullen zijn.

Eind 1954 waren er in Suriname alsmede op Curaçao en Aruba reeds jarenlang culturele centra werkzaam, die als autonome zusterstichtingen van de toenmalige Sticusa - opgericht in 1948 - een belangrijke coördinerende en stimulerende rol vervulden bij de ontplooiing van culturele activiteiten.

Het doel van de in 1948 opgerichte 'Sticusa,' die haar activiteiten ook uitstrekte tot Indonesië, was o.m. het nastreven van goede culturele betrekkingen tussen Nederland, Suriname en de Nederlandse Antillen. $\mathrm{Na}$ het uitvallen van Indonesië als partner werd eind 1955 de huidige Sticusa opgericht, die tot doel heeft "het versterken van de culturele banden tussen Nederland, Suriname en de Nederlandse Antillen." Statutair is het belangrijkste middel om tot verwezenlijking van dit doel te geraken "het stimuleren en zo nodig zelf verrichten van al datgene wat dient tot uitwisseling van personen, goederen en diensten op cultureel gebied met Suriname en de Nederlandse Antillen en waar nodig met andere landen."

Gedurende de jaren I956 en volgende is de in de statuten genoemde uitwisseling van personen, goederen en diensten op cultureel gebied, die reeds in de periode I948-I955 geen overwegende rol speelde, steeds meer op de achtergrond geraakt; de kosten, samenhangend met de uitzending van personen, het aankopen en expediëren van goederen, het subsidiëren van de in omvang en aantal gestadig toegenomen zusterstichtingen alsmede het verlenen van diensten door Nederland in het kader van de culturele bijstand, zijn verreweg het grootste deel van het Sticusabudget gaan opeisen. Bij het steeds meer op de voorgrond treden van de culturele bijstand werd het werk van de Sticusa ook uitgebreid tot buiten het terrein van de zusterstichtingen.

1 R. H. Pos: 'De culturele betrekkingen tussen de Rijksdelen in verband met het Statuut voor het Koninkrijk,' verschenen in Culturele activiteit in Suriname, Gedenkboek CCS, 1957. 
Immers de overheden en ook andere culturele organisaties overzee hebben in toenemende mate een beroep gedaan op de medewerking van de Sticusa. Hierbij heeft deze instelling tot richtsnoer genomen niets te willen opdringen en zich in hoofdzaak er toe te bepalen verzoeken van overzee af te wachten, deze zo goed mogelijk te verwezenlijken en ten hoogste in bepaalde gevallen adviserend en stimulerend op te treden.

De hierboven geconstateerde vergroting van het terrein van culturele bijstand werd mede in de hand gewerkt door de Nederlandse overheid, die de mening is toegedaan, dat voorzover voor de verwezenlijking van culturele projecten ten behoeve van Suriname en de Nederlandse Antillen ook een beroep wordt gedaan op de materiële en financiële medewerking van Nederland, het verlenen daarvan zo veel mogelijk door de bedding van één 'kanaal,' te weten de Sticusa, moet worden geleid. Een duidelijk voorbeeld hiervan is de medio Ig6o op gang gekomen verzending van op telerecording vastgelegde N.T.S.-programma's ten behoeve van de televisie op de Nederlandse Antillen.

Samenvattend kan worden gezegd, dat de Sticusa thans in de eerste plaats fungeert als een administratief centrum, dat cultureel-technische bijstand organiseert ten behoeve van de partnerlanden in het Caraïbische gebied en daarnaast als een bureau met een beperkte, op Nederland gerichte, activiteit voornamelijk op het terrein van de voorlichting.

Ofschoon deze arbeid tot dusverre niet zonder resultaten is gebleven, zijn aan het zonder meer continueren daarvan ook bezwaren verbonden, waarop in het laatste deel van deze beschouwing zal worden teruggekomen.

Ter illustratie van de hierboven vermelde terreinvergroting met betrekking tot de culturele bijstand kunnen verscheidene organisaties worden genoemd, welke gedurende de afgelopen tien jaren zijn ontstaan en die financiële en/of materiële steun ontvangen: de culturele centra op Bonaire, St. Maarten en in Nickerie en Coronie; voorts de muziekscholen te Paramaribo en Willemstad, het 'Taalbureau Suriname,' de 'Vereniging van Wetenschappelijke Werkers' te Paramaribo, het 'Caraïbisch Marien-Biologisch Instituut' op Curaçao, de 'School voor Beeldende Kunsten' te Paramaribo, de 'Stichting Volkslectuur Suriname', de 'Surinaamse Historische Kring,' enz.

Hieruit blijkt, dat de Sticusa ook steun verleent aan de be- 
oefening van wetenschappelijke arbeid. Deze steun staat echter ver achter bij hetgeen de 'Natuurwetenschappelijke STUDIEKRING voor Suriname en de Nederlandse Antillen' (sinds I945) en de 'Stichting Wetenschappelijk Onderzoek Suriname-Nederlandse Antillen' (Wosuna) tot stand hebben gebracht.

De Wosuna werd op 26 februari I954 opgericht; reeds op 20 oktober daarop volgend kon het wetenschappelijk instituut van deze stichting te Paramaribo worden geopend. Van 1954 tot en met 1963 werd financiële steun verleend aan projecten op het terrein van de humaniora, natuurwetenschappen en medische wetenschappen. In 1964 werd deze instelling geliquideerd. Haar taak is overgenomen door de 'Stichting voor Wetenschappelijk Onderzoek van de Tropen' (WoTRo), die een geografisch wijdere doelstelling heeft.

Van groot belang voor de wetenschapsbeoefening is ook gebleken de reeds genoemde, in I955 opgerichte 'Stichting Caraibisch Marien-Biologisch Instituut' (CARMABI), gevestigd op Curaçao.

\section{II}

De beoefening van de taalkunde in Suriname en op de Nederlandse Antillen won gedurende de jaren na I945 sterk aan intensiteit.

Voor wat het Papiamentu betreft moge worden gewezen op publicaties van Luis DaAL, C. F. A. van Dam, W. M. Hoyer, G. P. Jansen, M. D. Latour, Raul Römer, P. H. J. UittenBogaARD en A. J. Maduro. Van de hand van E. R. Goilo verscheen in 1958 een instructief Papiaments leerboek.

Het multilinguale karakter van Suriname bracht met zich mede, dat van elke in dat land voorkomende taal een aantal studies, waaronder drie proefschriften, ${ }^{1}$ verschenen, die tezamen een indrukwekkende reeks vormen. Ook werd in verschillende publicaties de functie en problematiek met betrekking tot het Nederlands in Suriname belicht.

Het jaar I96I was van grote betekenis voor de coördinatie van het taalkundig onderzoek in Suriname door de oprichting van de 'Stichting Taalonderzoek Suriname'. Deze instelling heeft ten doel het verrichten van taalonderzoek, in het bijzonder

1 L. L. E. RENS: The historical and social background of Surinam's Negro-English, I953. J. VOORHOEVE: Voorstudies tot een beschrijving van het Sranan Tongo, 1953. J. J. VoskuIL: Het Nederlands van Hindoestaanse kinderen in Suriname, 1956. 
in multilinguale gebieden, en het dienstbaar maken van de resultaten van het wetenschappelijk onderzoek in de eerste plaats aan het onderwijs en voorts aan diverse andere praktische doeleinden. Omtrent de vraag welke projecten op het programma moeten worden geplaatst, zijn inmiddels prae-adviezen uitgebracht. Voorts bereidt de stichting conferenties voor betreffende het taalonderwijs in Suriname.

Hoewel niet geheel vallend binnen het bestek van dit onderwerp moge hier tevens worden vermeld de oprichting van de 'Stichting Volkslectuur Suriname' in I958, waartoe de Sticusa het initiatief nam en welke onder leiding van dr. L. A. M. LichTVELD haar werkzaamheden aanving. Uitgaande van de gedachte, dat lectuurvoorziening op zo groot mogelijke schaal in Suriname mede van grote betekenis is voor de sociaal-culturele ontwikkeling, stelt de stichting zich ten doel het verlenen van technische bijstand van elke aard bij het voorbereiden, ontwerpen, vervaardigen, uitgeven en distribueren van volkslectuur in opdracht van de Regering van Suriname. Onder volkslectuur wordt hier verstaan: leesstof ten behoeve van al degenen, die reeds aanvankelijk leesonderwijs hebben genoten, maar nog niet zulk een graad van ontwikkeling of geoefendheid hebben bereikt, dat lezen tot iets gewoons geworden is. Allereerst werd een lijst van 8 oo Nederlandse basiswoorden samengesteld, waarvan het gebruik de leesbaarheid en verstaanbaarheid van de inmiddels door het bureau in de Nederlandse taal uitgegeven publikaties ongetwijfeld ten goede is gekomen.

Het dilemma van Suriname, dat grote hoeveelheden lectuur snel nodig zijn en jaren van achterstand moeten worden ingehaald, maakt de lectuurvoorziening en dus ook de taak van het Bureau Volkslectuur dermate urgent, dat een grotere deelname van de Surinaamse overheid dan tot dusverre werd verkregen dringend nodig is, zowel in financieel als organisatorisch opzicht. Over de toestand op literair terrein is door verschillende meer bevoegde auteurs ook in dit tijdschrift reeds geschreven. ${ }^{1}$ In dit verband zal ik mij derhalve beperken tot de opmerking, dat er van uitwisseling van literaire kennis tussen de drie landen van het Koninkrijk in 1954 nog slechts weinig sprake was.

1 Zie o.m. Johanna Felhoen Kraal: 'Caribische letteren', verschenen in De West-Indische Gids 35, 1955. 
Overzee was de kennis van auteurs in Nederland veel groter dan omgekeerd. Over het algemeen behoort deze eenzijdige situatie nog niet tot het verleden, hoewel enige verbetering kan worden geconstateerd. Auteurs als Albert Helman en Colá Debrot genieten in Nederland grote bekendheid maar ook jongere auteurs als de Antillianen Boelie van Leeuwen en Tip Marugg zijn hier te lande geen onbekenden meer. Vooruitlopend op het slot van deze beschouwing zou ik in dit verband de wenselijkheid willen bepleiten van een sterke intensivering van bezoeken van letterkundigen uit de drie landen aan de partnerlanden.

De Sticusa heeft steeds grote waarde gehecht aan de lectuurvoorziening overzee door middel van boeken en tijdschriften. Dat de leesbehoefte mede door de omvangrijke zendingen uit Nederland is gestimuleerd staat vast, hetgeen ook met voorbeelden kan worden aangetoond. Blijkens een door de Wereldomroep ingestelde boekenenquête op Aruba had $69 \%$ van de Antilliaanse inwoners van dat eiland een voorkeur voor het Nederlandse boek boven buitenlandse lectuur. Een ander voorbeeld: van de rond 6200 uitleningen van de Wetenschappelijke Bibliotheek op Curaçao in $1963 \mathrm{kwam} 7 \mathrm{r} \%$ voor rekening van de Antilliaanse inwoners; in 1958 bedroeg dit percentage nog slechts 38 .

In de boekenvoorziening van Suriname droeg de Sticusa voor de periode van I948-I964 met ongeveer roo.ooo banden bij. Een groot aandeel hierin had de bibliotheek van het 'Cultureel Centrum Suriname' (CCS). Het aantal door deze boekerij verzorgde uitleningen te Paramaribo steeg van 25.000 in 1954 tot I20.000 in I963, dankzij ook de inmiddels tot stand gekomen filialen in de buitenwijken van de stad. Van het laatstgenoemde aantal behoorden 78.000 tot de categorie jeugdboeken. Sedert I96o ging de CCS-boekerij ook regelmatig wisselcollecties samenstellen voor de districten buiten Paramaribo. Het in bedrijf komen van een in 1963 door de Sticusa beschikbaar gestelde bibliobus zal deze activiteit aanzienlijk kunnen intensiveren.

Van grote betekenis is ook de tijdschriftenvoorziening, die sedert I 960 sterk is toegenomen dankzij de bemiddeling van de 'Nederlandse Organisatie van Tijdschriften Uitgevers' (NoTU) waardoor jaarlijks circa 70.000 stuks geillustreerde Nederlandse populaire weekbladen beschikbaar komen voor de Antilliaanse en Surinaamse schooljeugd en de ouders. Men moet de betekenis, die deze 'injecties' van tijdschriften hebben, in het licht van het 
feit, dat beide landen tezamen slechts circa 550.000 inwoners tellen, niet onderschatten. De Nederlandse schooljeugd is momenteel, wat haar kennis over de landen in het Caraïbisch gebied aangaat, voorlopig nog heel wat minder bevoorrecht. Gelukkig bestaat sedert kort uitzicht op verbetering.

Wat de actieve beoefening van de filmkunst betreft valt te melden, dat sedert 1957 in Suriname een filmproduktiegroep werkzaam is, die, na tevoren een aanvullende opleiding in Nederland te hebben ontvangen, in opdracht van de Surinaamse Regering hoofdzakelijk documentaire films vervaardigt, die een voorlichtende functie hebben. De film is een zeer belangrijk communicatiemiddel gebleken in deze tijd van diepgaande structurele veranderingen op sociaal en economisch terrein, waarin Suriname thans verkeert. Ook de Nederlandse Antillen bevinden zich in deze situatie, zodat het geen verwondering zal wekken, dat in 1964 is begonnen met de opleiding in Nederland van twee Antilliaanse cineasten.

Wat de passieve beleving van de filmkunst betreft dient te worden gememoreerd, dat het filmmenu in de commerciële bioscopen in Suriname en de Nederlandse Antillen voor het grootste deel uit Amerikaanse kost bestaat. Een in omvang geleidelijk toenemend tegenwicht vormt hetgeen de in beide landen bloeiende filmliga's maandelijks hun leden voorzetten, daartoe in belangrijke mate in staat gesteld door de Sticusa. Daarnaast zijn de filmotheken van het CCS en het CCC ('Cultureel Centrum Curaçao') over een groot aantal door de Sticusa aangekochte speelfilms, onderwijsfilms en kinderfilms gaan beschikken, die ook buiten de steden onder de aandacht van een groot publiek kunnen komen o.m. door middel van cinétrucks. Deze faciliteiten hebben er mede toe bijgedragen, dat men enigszins raakt uitgekeken op de 'westerns,' die dan ook niet meer tot het soort films behoren, dat de hoogste recettes oplevert.

De muziekbeoefening onderging een sterke uitbreiding. Op Aruba bestond reeds in I95I een muziekschool; in Suriname en op Curaçao werden dergelijke instituten respectievelijk in 1956 en I96o opgericht. Gezamenlijk tellen de drie scholen thans meer dan Iooo leerlingen, waarop 9 door de Sticusa uitgezonden krachten les geven en daarnaast een nog groter aantal Antilliaanse en Surinaamse docenten. In het algemeen bestaat bij het Surinaamse en Antilliaanse kind een grote belangstelling en aanleg voor het 
gebruik van ritmische uitdrukkingsmiddelen. Hieraan kon o.m. op gelukkige wijze worden tegemoetgekomen door de aanschaf van een Orff-instrumentarium ten behoeve van de Arubaanse muziekschool. De hiermee bereikte resultaten waren zo opmerkelijk, dat dit initiatief binnenkort door de andere muziekscholen zal worden overgenomen.

Aan de reeds vóór 1954 bestaande symphonie-orkesten op Aruba, Curaçao en te Paramaribo werden nieuwe ensembles toegevoegd: de 'Surinaamse Kamermuziekvereniging,' het Jeugdorkest en diverse koren.

De beoefening van de autochthone muziek moet, vanwege de beperkte plaatsruimte, buiten het bestek van dit artikel blijven.

De beoefening van het toneel gedurende de afgelopen jaren heeft tot de conclusie geleid, dat niet zelden de grootste successen worden bereikt met stukken, die hetzij een sociale achtergrond hebben, hetzij - van origine afkomstig uit landen buiten Suriname en de Nederlandse Antillen - zodanig worden bewerkt, dat zij geheel passen in de 'couleur locale.'

Als voorbeeld van de eerste categorie moge gelden de Surinaamse bewerking van Brusse's 'Boefje,' getiteld Sjinnie, welke in 1956 voor ruim 21.000 bezoekers 30 opvoeringen beleefde. De voorstellingen, die plaatsvonden onder auspiciën van het toneelgenootschap 'Thalia,' dat in 1962 zijn I25-jarig bestaan vierde, werden geregisseerd door EDwIN Tномаs.

Een voorbeeld van de tweede categorie is o.m. de serie opvoeringen van de door mevrouw M. HENRIQUEZ-Alvarez CoRrea verzorgde Papiamentse bewerking van Shaw's 'Pygmalion,' dat onder regie van het echtpaar Kamerman-RuimschотеL op de Nederlandse Antillen daverend succes oogstte.

Een hoofdstuk apart vormen de opvoeringen in Suriname van het Caraïbisch passiespel van Albert Helman, die diepe indruk maakten. De auteur is er in dit stuk in geslaagd de verhevenheid van het passiegebeuren in een Surinaams kader te plaatsen.

Voorts moge niet onvermeld blijven het buitengewone succes, behaald door de regisseur Ton Verwey met Datra Sjorie, een bewerking in het Sranang Tongo door WILFRED GRIMÈrE van Molière's 'Le médecin malgré lui.' Aan dit als wagenspel gebrachte stuk beleefden 26.000 toeschouwers plezier in 34 opvoeringen; 16 hiervan werden in de districten gespeeld waarvan verschillende in plaatsen, waar de bewoners nog nooit iets dergelijks hadden gezien. 
Op Aruba, Curaçao en te Paramaribo bestonden gedurende de afgelopen tien jaren balletscholen, vaak onder leiding van uit Nederland gezonden balletdeskundigen. Belangwekkend was het streven van Maria Huisman, die van I956 tot I96o de balletschool te Paramaribo leidde. Met balletten als 'Sranang printjie boekoe' (= Surinaams prentenboek) en 'De rode palulu' heeft zij een vermenging bewerkstelligd van de klassieke techniek met de Surinaamse en Zuidamerikaanse dansen. De muziek van beide balletten was gecomponeerd door de Surinaamse musicus EDDY VERVUURT, hetgeen tot een zeer gelukkig resultaat leidde. Ook het moderne ballet, dat door de in Nederland opgeleide AsTrid SALAZAR op de Nederlandse Antillen werd gebracht, bleek een zeer bruikbaar uitgangspunt, getuige het feit, dat ook haar leerlingen zich op deze wijze in de danskunst geheel konden uitleven.

In Suriname en op de Nederlandse Antillen werden gedurende het afgelopen decennium resp. I9 en 26 uit Nederland afkomstige exposities gehouden, hoofdzakelijk op het terrein van de beeldende kunst. Vermeldenswaard is hierbij, dat het in drie gevallen exposities betrof van in Nederland woonachtige Surinaamse schilders. Andere exposities gaven een indruk van het leven in Nederland of behandelden speciale onderwerpen. Omgekeerd kwam ook het werk van Antilliaanse en Surinaamse kunstenaars onder de aandacht van het publiek in Nederland. ${ }^{1}$

Het aantal exposities in Nederland, dat algemene voorlichting geeft inzake de landen overzee, begint de laatste jaren gelukkig toe te nemen.

Dat de belangstelling en het begrip voor de beeldende kunsten in Suriname en de Nederlandse Antillen de laatste jaren sterk groeit, blijkt o.m. uit het volgende: I. de totstandkoming van teken- en schildercusussen en een school voor beeldende kunsten; 2. het grote aantal exposities dat op Surinaams of Antilliaans initiatief wordt gehouden van werk van kunstenaars binnen en buiten deze landen (waarbij, naast 'Het Curaçaosche Museum,' de totstandkoming van 'Galerie de Boog' in Willemstad, met

1 Tijdens het samenstellen van dit artikel bereikte ons het bericht van de onthulling van het beeld ter nagedachtenis van de gevallen vliegers van de KLM. De opdracht daartoe was gegeven aan de Surinaamse beeldhouwer ERWIN DE VRIES: een gelukkig voorbeeld van culturele integratie in Rijksverband! 
ere moge worden vermeld); 3 . het aantal opdrachten vanwege de Surinaamse en Antilliaanse overheden, vooral op het terrein van de beeldhouwkunst, aan buitenlanders en kunstenaars uit eigen land. Dat de aanvaarding van de ontwerpen nog wel eens moeilijkheden oplevert, is geen reden tot verontrusting; eerder kan men er zich over verheugen, dat de dialoog tussen de gemeenschappen overzee en de moderne kunst nu tenminste op gang is gekomen.

De confrontatie van de pers in Suriname en de Nederlandse Antillen met hetgeen er, vooral op cultureel terrein, leeft in Nederland en West-Europa geschiedde de afgelopen jaren door toezending van artikelen: In I954 werden er 372 persartikelen verzonden, welk aantal in r 963 was opgelopen tot 9o3. Tweederde hiervan werd afgedrukt.

De verbondenheid tussen de drie landen wordt per radio vooral in stand gehouden door 'Radio Nederland Wereldomroep,' die haar werkterrein in dit opzicht omschrijft als "het onderhouden en versterken van de band met alle Rijksgenoten in de Rijksdelen overzee." Blijkens een door de Wereldomroep ingestelde enquête wordt de waardering overzee voor deze instelling vooral ook bepaald door de groetenprogramma's, waardoor een intensief contact blijft bestaan tussen Surinamers en Antillianen, die zich - merendeels tijdelijk - in Nederland hadden gevestigd en de verwanten overzee.

Met technische medewerking van de Wereldomroep konden jaarlijks meer dan ıoo radiocauserieën voor de transcriptieprogramma's van de radiostations overzee worden verzonden over de meest uiteenlopende onderwerpen.

Sedert medio I 960 vloeit door vruchtbare samenwerking van NTS, Wereldomroep en Sticusa een stroom van Nederlandse televisieprogramma's van algemeen-informatieve dan wel van verstrooiende aard naar de Antilliaanse televisie. Bedroeg het weekgemiddelde in de eerste maanden nog slechts ruim 40 minuten, thans kan de Antilliaanse kijker gemiddeld $2 \frac{1}{2}$ uur per week programma's volgen, die eerst in Nederland te zien waren. In enkele gevallen kon worden bewerkstelligd, dat een programma gelijktijdig door de Nederlandse en Antilliaanse televisie werd uitgezonden, zoals b.v. 'Oranjes over Oranjes" ter gelegenheid van de herdenking in het kader van ${ }_{50}$ jaar Koninkrijk. Der- 
gelijke gestes worden overzee hogelijk gewaardeerd en geven aan de verbondenheid een bijzonder reliëf.

In de loop der jaren is een belangrijke smaakverbetering van het Antilliaanse televisiepubliek te constateren, een ontwikkeling, die ook in andere landen heeft plaatsgehad. Men raakt uitgekeken op de vele Amerikaanse 'westerns' en 'gooi- en smijtfilms'. De waardering voor eigen produkties groeit vooral ook omdat het publiek daarin zijn eigen Antilliaanse identiteit gaat herkennen en op prijs stellen. In dit verband verdient b.v. vermelding het jeugdprogramma 'Hubentud na marcha.' Een ander tegenwicht tegen de Amerikaanse programma's, dat tevens tot de smaakverbetering heeft bijgedragen, mag stellig op rekening van de uit Nederland gezonden televisieprogramma's worden geschreven.

De beperkingen, die het kader van deze beschouwing nu eenmaal oplegt, maakten het nodig een nadere uiteenzetting betreffende vele andere feiten achterwege te laten; hiervan noem ik b.v. hetgeen tot stand is gekomen op het terrein van de monumentenzorg, de groei van het museumwezen, het archeologisch onderzoek, de ontwikkeling van de sociaal-culturele arbeid en de huidige stand van zaken ten aanzien van de onderwijsvoorlichting in Nederland betreffende Suriname en de Nederlandse Antillen.

III

Hetgeen tot dusverre is gebeurd met betrekking tot de culturele opbouw in Suriname en de Nederlandse Antillen is, gezien de korte tijd waarin zich de geschetste ontwikkelingen hebben afgespeeld, zeer zeker de moeite waard. Het wettigt de conclusie, dat de eerste fase (waarvan VAN LIER in 1956 gewag makte) ${ }^{1}$ waarin de grondslagen van de culturele opbouw moeten worden vastgesteld, thans veel verder en misschien zelfs grotendeels is doorlopen. Niettemin is de culturele ontwikkeling nog een prille zaak; bij haar verdere wasdom kunnen crisisverschijnselen optreden waarvoor vrees niet op zijn plaats is, omdat zij er nu eenmaal bij horen.

De vraag is in hoeverre deze crisis zich zonder al te grote schokken kan voltrekken. Is het voldoende wanneer het huidige tempo,

1 R. A. J. van Lier: 'Culturele ontwikkeling van Suriname en de Nederlandse Antillen', verschenen in 'Continent in groei,' speciaal nummer van $\mathrm{De}$ Gids, r956. 
waarin naar de voltooiing van de culturele grondslagen wordt toegewerkt, wordt aangehouden of is het nodig in een hogere versnelling over te schakelen?

Het antwoord moet naar mijn overtuiging luiden, dat een aanzienlijke opvoering van het tempo zal moeten plaatsvinden. Immers, veel van hetgeen in de culturele sector vooral gedurende de laatste jaren met grote inspanning en goed vertrouwen op blijvende financiële steun tot stand is gebracht, kan slechts dan voor verval en ondergang worden behoed indien een veel krachtdadiger financiële, organisatorische en materiële steun wordt gegeven dan tot dusver het geval was. Er zijn vooral de laatste jaren op eigen initiatief overzee vele nieuwe culturele instellingen aan de bestaande toegevoegd. De Sticusa heeft meegewerkt aan de totstandkoming van enkele dezer instellingen en hun activiteiten o.a. door het beschikbaar stellen van financiële middelen helpen 'aanzwengelen'. Daarbij heeft men in Nederland in de verwachting geleefd, dat met name de overheden ter plaatse deze steun grotendeels zouden overnemen, hetgeen helaas in zeer onvoldoende mate is gebeurd.

Een voorzichtige buitenstaander zou misschien tot de conclusie kunnen komen, dat voor het totstandbrengen van dit alles, gelet op de beperkte financiële mogelijkheden, wel jeugdige overmoed in het spel was en hij zou zich kunnen afvragen of het nu en dan niet wat te veel van het goede is geweest. Het antwoord luidt, dat het culturele bloed kruipt waar het niet gaan kan. Er is een voorlopig nog onstilbare, culturele honger ontstaan, welke zich niet meer door zeer geleidelijk afgepaste grotere of zelfs gelijkblijvende routine-menu's laat bevredigen.

Hier wreekt zich het feit, dat de culturele ontwikkeling te zeer is achtergebleven bij de enorme economische en sociale groei van Suriname en de Nederlandse Antillen.

Bij brood alleen zal de mens niet leven, staat er geschreven. De cultuur van een land is de uitdrukking van zijn nationale persoonlijkheid. Door hetgeen in de afgelopen jaren op het stuk van geestelijke bewustwording is gegroeid, werd de begeerte naar herkenning en versteviging van de eigen nationale identiteit, zoals deze zich in verleden en heden manifesteert, heviger. De culturele instellingen overzee en de samenwerkende organisaties in Nederland hebben zich tot dusverre teveel moeten richten op het bevredigen van de in omvang steeds groeiende onmiddellijke behoeften aan bijstand en te weining op het versterken van de 
culturele identiteit door nieuwe middelen, welke op zeer korte termijn nodig zullen zijn. Alleen dàn kan de zozeer begeerde gelijkwaardige geestelijke ontmoeting tussen de drie landen inhoud en richting krijgen. Hier is trouwens sprake van een wisselwerking. In dit verband moge worden verwezen naar de hiervoor bepleite uitwisseling van letterkundigen. Daarbij is niet alleen het Koninkrijk in het geding maar ook de groep omliggende landen in het Caraïbisch gebied. In de praktijk is de Sticusa er nog nauwelijks aan toegekomen de statutaire mogelijkheid te benutten om ook culturele uitwisseling te bedrijven met de omliggende landen in het Caraïbisch gebied en de mogelijkheid te scheppen daarin verkenningen te verrichten. Toch is de ontmoeting met deze cultureel verwante landen eveneens noodzakelijk voor het verdiepen van het inzicht in en het vinden van een oplossing voor vraagstukken, die in Suriname en de Nederlandse Antillen zelf leven.

In het licht van deze zich sedert I96o steeds duidelijker aftekenende problematiek werd in I96I de 'Adviesraad voor Culturele Samenwerking tussen de landen van het Koninkrijk' geboren; ook deze instelling ontleende zijn juridische basis aan het Statuut. Ten onrechte heeft men de Adviesraad wel eens het epitheton opgedrukt van voogdijraad. Veeleer moet hij gezien worden als een familieraad, die met zijn suggesties er toe wil bijdragen de voorwaarden te scheppen om de verdere culturele groei voor al te grote belemmeringen te vrijwaren.

In de door LiCHTVELD opgestelde beginselverklaring spreekt de Adviesraad uit, dat "het een gewichtige taak is van de overheid en van individuen om de culturele samenwerking zo krachtig en edelmoedig mogelijk te beoefenen." Even verder wordt betoogd, dat de gelden, die voor deze samenwerking nodig zijn, al naar draagkracht van de drie samenwerkende partijen ter beschikking moeten komen.

Is zulks ook gebeurd? Hebben de overheden overzee en in Nederland wel naar draagkracht het hunne bijgedragen aan het steeds steiler oplopend uitgavenaccres ten behoeve van de culturele samenwerking gedurende het afgelopen decennium?

Het ontkennende antwoord op deze vraag is met betrekking tot bepaalde activiteiten in het vorenstaande reeds gegeven. De zware financiële eisen, die inhaerent zijn aan investeringen in de sociaal-economische sector, rechtvaardigen naar mijn mening nog niet het feit, dat de bijdragen van de overheden overzee aan 
de culturele opbouw gedurende de afgelopen jaren nauwelijks enig accres te zien hebben gegeven; soms was zelfs sprake van een achteruitgang. ${ }^{1}$ Het subsidie van de overheid in Nederland aan de Sticusa is van 1956 tot 1964 met enkele tussentijdse inzinkingen weliswaar verdubbeld maar hierbij moet men voor ogen houden, dat een kwart van het in het laatstgenoemde jaar toegekende subsidie is bestemd voor projecten, waarvoor in 1956 nog geen gelden behoefden te worden uitgetrokken, n.l. televisie en scholenvoorlichting. Ter vergelijking moge dienen dat het budget van het Nederlandse Departement van Onderwijs, Kunsten en Wetenschappen in deze jaren bijna werd verviervoudigd, en dat in een land, dat tevoren reeds beschikte over een wijd vertakt cultureel apparaat. Niet zonder voldoening moge in dit verband melding worden gemaakt van het feit, dat de Nederlandse overheid - behoudens goedkeuring door de StatenGeneraal - voor 1965 het volle subsidiebedrag zal uitkeren, dat in het in 1959 opgestelde vijfjarenplan voor I964 was voorzien. Niet ten onrechte heeft de Adviesraad overigens reeds in r96r uitgesproken, dat het in dit plan voorziene uitgavenaccres te laag is geraamd. Zulks behoeft geen verwondering te wekken, omdat bij het opstellen van het plan de stormachtige ontwikkeling van I96o af niet in zijn volle omvang kon worden voorzien.

Albert Helman heeft parodiërend eens gezegd: "Die statuut, zie toe, dat hij niet valle."

Moge de Nederlandse Regering zich voor ogen houden, dat ontwikkelingshulp aan landen buiten het Koninkrijk en economische hulp aan Suriname en de Nederlandse Antillen zeer nuttig en nodig is, doch slechts met volle overtuigingskracht kan worden gegeven indien de eigen geestelijke banden binnen het Rijk hecht en hartelijk zijn. Het gulhartig en spontaan meewerken aan de culturele opbouw in Rijksverband is voor het bestendigen van deze hechtheid en hartelijkheid een wezenlijke voorwaarde.

Laten de Regeringen van Suriname en de Nederlandse Antillen

1 De overheidsuitgaven aan cultuur bedragen in Nederland de laatste jaren rond $\mathbf{I}, 9 \%$ van de totale Overheidsuitgaven. In Suriname en de Nederlandse Antillen was dit percentage nauwelijks o,4 \%, dus bijna vijf maal minder. In beide laatstgenoemde landen staat men weliswaar voor grote investeringen in de sociaal-economische sector maar daar staat tegenover, dat men zich geen offers behoeft te getroosten voor defensie, zoals in Nederland. 
zich niet te eenzijdig blijven toeleggen op de op zichzelf zeer belangrijke sociaal-economische ontwikkeling dezer landen. Mogen zij beseffen, dat wat in de afgelopen jaren met veel geestdrift en zorg is opgebouwd, niet door het uitblijven van de benodigde steun verloren mag gaan.

Amsterdam, oktober 1964 . 